\title{
Contribuições de uma sequência didática interdisciplinar em uma abordagem investigativa: a horta escolar no contexto
}

\section{Contributions of an interdisciplinary didactic sequence in an investigative approach: the school vegetable garden in the context}

\author{
Paulo Henrique de Souza* \\ Núbia Patielle Assis Carvalho* \\ Marta João Francisco Silva Souza
}

\section{Resumo}

O desinteresse dos estudantes durante as aulas é um dos fatores de preocupação e frustração relatados por muitos professores em trabalhos acadêmicos. Neste trabalho, apresentamos uma análise na perspectiva de três professoras na elaboração e no desenvolvimento de uma sequência didática interdisciplinar por meio de atividades investigativas para uma turma de $6^{\circ}$ ano do ensino fundamental de uma escola pública municipal rural na região sudoeste do estado de Goiás. Este artigo é um recorte de uma pesquisa de mestrado profissional em Educação para Ciências e Matemática, que se configura como uma possibilidade de ação interdisciplinar no contexto escolar. A coleta de dados foi realizada por meio de entrevistas semiestruturadas e observações assistemáticas, as questões da entrevista tiveram como objetivo conhecer o perfil das professoras e sua percepção quanto à proposta interdisciplinar, à turma, às metodologias utilizadas, às possíveis mudanças detectadas no comportamento dos alunos e às dificuldades encontradas. $\mathrm{O}$ desenvolvimento deste trabalho propiciou às professoras realizar uma reflexão sobre suas práticas pedagógicas, já que puderam observar as mudanças na participação dos alunos, na dinâmica de sala de aula, bem como na aprendizagem dos conteúdos abordados.

Palavras-chave: Abordagem investigativa. Horta escolar. Interdisciplinaridade.

\section{Abstract}

The lack of interest of students in class is one of the factors of concern and frustration reported by many teachers in academic papers. In this work we present an analysis from the perspective of three teachers in the elaboration and development of an interdisciplinary didactic sequence through investigative activities for a 6th grade elementary school class in a rural municipal public school in the southwest region of the state of Goiás. This article is a snip of a professional master's research in Education for Science and Mathematics that is configured as a possibility of interdisciplinary action in the school context. Data collection was done through semi-structured interviews and unsystematic observations. The interview questions had as objective to know the profile of the teachers and their perception regarding the interdisciplinary proposal, the class, the methodologies used, the possible changes detected in the behavior of the students and the difficulties encountered. The development of this work allowed the teachers to reflect on their pedagogical practices, since they could observe the changes in the participation of the students; the dynamics of the classroom, as well as the reflexes in learning the contents studied.

Keywords: Investigative approach. School vegetable garden. Interdisciplinarity.

Recebido em 07/11/2017 - Aprovado em 19/02/2018

http://dx.doi.org/10.5335/rep.v25i2.8167

Doutor em Física pela Universidade de São Paulo. Docente permanente do Programa de Pós-Graduação em Educação para Ciências e Matemática e Professor de Física no Instituto Federal de Educação, Ciência e Tecnologia de Goiás - Campus Jataí. E-mail: phsouzas@gmail.com

** Mestre em Educação para Ciências e Matemática. Professora de Matemática da rede pública municipal de Jataí, GO. E-mail: nubiapatielle@gmail.com

*** Mestre em Física pela Universidade Federal de Goiás. Professora de Física no Instituto Federal de Educação, Ciência e Tecnologia de Goiás - Campus Jataí. E-mail: martajfss@gmail.com 


\section{Introdução}

Pozo e Crespo (2009) afirmam que é comum, entre os professores de Ciências, principalmente dos anos finais do ensino fundamental e do ensino médio, um sentimento de frustração diante do pouco sucesso alcançado por seu trabalho docente. "Aparentemente, os alunos aprendem cada vez menos e têm menos interesse pelo que aprendem" (POZO; CRESPO, 2009, p. 15). Segundo os autores, essa crise da educação científica leva à perda de sentido do conhecimento científico pelo aluno, limitando sua aplicabilidade e diminuindo sua relevância ou interesse, pois se observa que,

[...] como consequência do ensino recebido, os alunos adotam atitudes inadequadas ou mesmo incompatíveis com os próprios fins da ciência, que se traduzem sobretudo em uma falta de motivação ou interesse pela aprendizagem desta disciplina de ciências (POZO; CRESPO, 2009, p. 17).

Sasseron (2013) destaca que: "Hoje em dia, não apenas a cultura escolar influencia a abordagem de conteúdos, mas também, e sobretudo, a cultura daqueles que estão na sala de aula influencia a cultura escolar e a abordagem de conteúdos" (2013, p. 41). Tais influências apontam a necessidade de relacionar os conteúdos estudados com o cotidiano dos alunos, o que exige do professor a busca por um ensino que coloque o aluno e suas vivências no centro do seu processo de formação. Nessa perspectiva, o ensino construtivista se destaca, pois se afasta da ideia de "repetição e acumulação de conhecimento", cabendo ao professor aprender a "transformar a mente de quem aprende, que deve reconstruir em nível pessoal os produtos e processos culturais com o fim de se apropriar deles" (POZO; CRESPO, 2009, p. 20).

Dentre vários autores, Sasseron (2008) defende que o ensino de Ciências, em qualquer nível escolar, deve ocorrer por meio de ações nas quais os alunos devem investigar problemas e fenômenos, levantando e testando hipóteses, construindo conclusões sobre os resultados alcançados e relacionando-os com a sociedade e o meio ambiente. A autora destaca que é necessário buscar um ensino que:

[...] permita aos alunos interagir com uma nova cultura, com uma nova forma de ver o mundo e seus acontecimentos, podendo modificá-lo e a si próprio através da prática consciente propiciada por sua interação cerceada de saberes e noções e conhecimentos científicos, bem como das habilidades associadas ao fazer científico (SASSERON, 2008, p. 12).

Assim, “[...] o ensino de Ciências pode e deve partir de atividades problematizadoras, cujas temáticas sejam capazes de relacionar e conciliar diferentes áreas e esferas da vida de todos nós [...]" (SASSERON; CARVALHO, 2011, p. 66), de forma a permitir que os alunos percebam a relação das ciências com seu dia a dia. Uma proposta desse tipo, se desenvolvida nos anos finais do ensino fundamental, 
favorece que o professor trabalhe numa perspectiva interdisciplinar, relacionando disciplinas, conteúdos e outros professores. Essa perspectiva é necessária para 0 estudo de alguns objetos de conhecimento devido à sua complexidade. "O clima, a cidade, o trânsito, o ambiente, a cognição, são exemplos [...] que só existem como objectos de investigação porque, justamente, é possível pôr em comum, várias perspectivas interdisciplinares" (POMBO, 2008, p. 24).

Augusto et al. (2004) entendem a interdisciplinaridade como "[...] a necessidade de integrar, articular, trabalhar em conjunto" (AUGUSTO et al., 2004, p. 278) e apontam que os protagonistas na implantação de práticas interdisciplinares na escola são os professores.

Rosa, Rosa e Giacomelli (2016) observaram que, apesar de o tema interdisciplinaridade ser bastante debatido tanto na comunidade científica como na escolar, é escassa a existência de propostas efetivas ao alcance dos professores. Os autores chamam a atenção para a necessidade de que os "[...] pesquisadores olhem para a sala de aula e estudem possibilidades de transpor a produção acadêmica em situações didáticas" (ROSA; ROSA; GIACOMELLI, 2016, p. 536).

Este artigo é um recorte de uma pesquisa de mestrado profissional em Educação para Ciências e Matemática, que se configura como uma possibilidade de ação interdisciplinar no contexto escolar. $O$ trabalho partiu da insatisfação de três professoras de uma turma de $6^{\circ}$ ano do ensino fundamental de uma escola rural da cidade de Jataí, estado de Goiás, uma das quais é a pesquisadora, diante de dificuldades de aprendizagem, desmotivação, passividade e indisciplina apresentadas pelos alunos. O sentimento de frustração diante do fracasso dos alunos trouxe a necessidade de repensar as aulas, até então expositivas, buscando formas de ensinar capazes não apenas de motivar e instigar os alunos a participar do processo de formação, mas também de contribuir para sua formação como cidadão.

Com base nesta problemática e pensando na interdisciplinaridade como eixo norteador do processo de ensino e aprendizagem, encontrou-se nas atividades investigativas uma possibilidade para a solução dos problemas detectados. Neste artigo, apresenta-se uma sequência didática (SD) interdisciplinar baseada em atividades de investigação, elaborada e implementada pelas professoras, e busca-se identificar suas percepções quanto às dificuldades encontradas, às contribuições e limitações da SD para os alunos e ao trabalho interdisciplinar desenvolvido.

Sabe-se que o termo interdisciplinaridade apresenta várias definições. Neste trabalho, adota-se a ideia defendida por Pombo:

Algo que, quando se ultrapassa essa dimensão do paralelismo, do pôr em conjunto de forma coordenada, e se avança no sentido de uma combinação, de uma convergência, de uma complementaridade, nos coloca no terreno intermédio da interdisciplinaridade (2008, p. 13). 
Essa ideia é complementada por Trindade (2008), que destaca que a interdisciplinaridade possibilita "[...] uma ruptura com o tradicional e com o cotidiano tarefeiro escolar" (TRINDADE, 2008, p. 82). Portanto, o professor que se propõe a trabalhar de maneira interdisciplinar não tomará para si "seu conhecimento", "sua disciplina", "seus conceitos", mas se permitirá vivenciar com o outro, "[...] possibilitando a interdependência, o compartilhamento, o encontro, o diálogo e as transformações. Esse é o movimento da interdisciplinaridade caracterizada por atitudes ante o conhecimento" (TRINDADE, 2008, p. 82).

\section{Atividades investigativas}

O processo de ensino e aprendizagem de Ciências deve preocupar-se em utilizar atividades e propostas que sejam instigantes aos alunos, referindo-se tanto "[...] à resolução de problemas e à exploração de fenômenos naturais [...] como também às discussões instigantes devido a sua própria temática" (SASSERON; CARVALHO, 2011, p. 73).

O ensino por investigação deve partir de atividades que despertem nos alunos o interesse pela descoberta e pela participação na resolução de determinado problema ou discussão, propiciando um espaço no qual possam levantar hipóteses, justificar seus pensamentos e argumentar sobre determinado assunto, o que é fundamental para o processo de ensino e aprendizagem. Carvalho (2010) diz que uma atividade pode ser considerada como atividade de investigação quando não se limita apenas à manipulação, pois também deve levar o aluno a reflexões, discussões e explicações, características de uma investigação científica. A autora aponta para a necessidade de espaços nas aulas de Ciências que possibilitem ao aluno a passagem da ação manipulativa para a intelectual e da ação intelectual para a manipulativa, pois é neste momento que novas hipóteses são elaboradas, sendo papel do professor apresentar questões para que os alunos pensem no que foi feito durante o processo de manipulação para a solução do problema.

O ensino por investigação traz os alunos para o centro do seu processo formativo, pois propicia a eles "[...] condições de trazer seus conhecimentos prévios para iniciarem os novos, terem ideias próprias e poder discuti-las com seus colegas e com o professor [...]" (CARVALHO, 2013, p. 9). Segundo Carvalho (2013), esses momentos de debate em sala de aula promovem uma passagem da linguagem cotidiana trazida pelas próprias experiências para uma linguagem científica. 


\section{Sequência de ensino por investigação}

As etapas propostas por Carvalho (2013) para se desenvolver uma sequência de ensino investigativa nas aulas de Ciências são: divisão da turma em grupos; distribuição do material experimental e apresentação do problema pelo professor; resolução do problema pelos alunos; sistematização dos conhecimentos aprendidos pelos alunos, que é dividida em duas partes (sistematização coletiva e sistematização individual).

Para resolver o problema proposto, os alunos manipulam os materiais, levantam e testam hipóteses a partir do seu conhecimento prévio e das discussões com os outros membros do grupo, até chegarem a uma solução. Durante a sistematização coletiva, o professor questiona os alunos "como" e "por quê" o problema foi resolvido de determinada maneira. Segundo Carvalho: "Ao ouvir o outro, ao responder à professora, o aluno não só relembra o que fez, como também colabora na construção do conhecimento que está sendo sistematizado" (2013, p. 12). Na sistematização individual, o aluno registra por escrito e/ou desenhos todo o processo, complementando toda a discussão realizada anteriormente.

No final das etapas mencionadas, caso o professor tenha dúvidas se os alunos compreenderam o conceito trabalhado, Carvalho (2013) sugere a leitura e a discussão de um texto de sistematização, a fim de retomar a resolução do problema e os principais conceitos e ideias envolvidos.

As atividades de contextualização social são aquelas nas quais os alunos podem estabelecer conexões entre o experimento realizado e situações do seu cotidiano. Dependendo dos objetivos pretendidos pelo professor, podem ser realizadas apenas por meio de questionamentos durante a sistematização coletiva. Nos casos em que é necessário um maior aprofundamento do assunto, novas atividades precisam ser planejadas, para as quais o professor pode utilizar diferentes materiais didáticos, como figuras, textos, jogos, vídeos e/ou simulações, etc. (CARVALHO, 2013). Segundo a autora, o mais importante ao se planejar essas atividades, é que elas também tenham características investigativas, possibilitando aos alunos momentos de discussão em grupo e a sistematização do professor.

O processo de avaliação proposto por Carvalho (2013) deve ser formativo, considerando não só os conteúdos conceituais, mas também os atitudinais e procedimentais, o que possibilita ao professor avaliar todo o processo, desde a resolução do problema. 


\section{Sequência didática - Horta escolar: investigando e melhorando o plantio}

A escola na qual foi desenvolvido este projeto está localizada na zona rural do município de Jataí, no estado de Goiás, é de responsabilidade do governo municipal e disponibiliza educação infantil, jardins I e II, e ensino fundamental, do $1^{\circ}$ ao $9^{\circ}$ ano, cujas novas instalações foram inauguradas no ano de 2014.

Considerando que a escola está localizada na zona rural e que os alunos da turma residem em fazendas e assentamentos rurais próximos, o tema escolhido para o desenvolvimento da proposta foi "horta escolar", um assunto que faz parte do cotidiano deles. Assim, a SD desenvolvida tinha como objetivo responder a seguinte questão: "como melhorar a produção de alimentos da horta escolar?". Após a escolha do tema, foi feita uma análise da matriz escolar para o $6^{\circ}$ ano pelas professoras de Ciências (PC), Geografia (PG) e Matemática (PM), para a definição dos conteúdos a serem abordados na SD: sistemas de irrigação, área da horta escolar e de seus canteiros e os tipos de solo.

A SD intitulada "Horta escolar: investigando e melhorando o plantio", descrita a seguir, tem caráter investigativo, foi elaborada de acordo com Zabala (1998) e planejada para ser desenvolvida em dezoito aulas de cinquenta minutos em uma turma de $6^{\circ}$ ano do ensino fundamental. A referida turma é composta por dezessete alunos com faixa etária entre 11 e 13 anos. A aplicação da SD ocorreu nos meses de novembro e dezembro de 2015.

\section{Aulas 1, 2 e 3: molhando as plantinhas}

As primeiras três aulas foram utilizadas para a realização de um experimento adaptado de uma atividade desenvolvida pelo Laboratório de Pesquisa em Ensino de Física (LaPEF), conhecida como "O problema da pressão", ${ }^{1}$ com o objetivo de compreender a relação da pressão da água com a altura da coluna d'água. O experimento investigativo proposto foi intitulado "Molhando as plantinhas" (CARVALHO, 2016, p. 144-145), e, segundo Carvalho e Souza (2017), teve o mesmo objetivo do experimento do LaPEF, mas foi construído com materiais de baixo custo, e também possibilita a compreensão do funcionamento de diferentes tipos de sistemas de irrigação.

A PC distribuiu os conjuntos experimentais sobre as mesas, dividiu a sala em grupos e propôs o desafio: "Como podemos fazer para aguar as plantinhas, sem retirar e sem apertar a mangueira?". Para resolver o problema, os alunos deviam molhar duas plantinhas fixadas na base da caixa retangular, localizadas a distâncias diferentes em relação à saída de água da mangueira. Para isso, precisavam 
colocar água no conjunto ligado à mangueira e variar a altura do recipiente, de modo a variar a pressão hidrostática e, portanto, o alcance do jato d'água.

Os alunos trocaram ideias e desenvolveram o experimento. Quando conseguiram resolver o desafio, a PC substituiu o conjunto de mangueira por uma mangueira furada e pediu que eles resolvessem o problema novamente. $\mathrm{O}$ objetivo, então, era que os alunos percebessem como os furos influenciam a vazão da água que sai da mangueira e comparassem o experimento com alguns sistemas de irrigação.

Após todos resolverem o problema, os alunos foram acomodados em círculo para a sistematização coletiva, mediada pela PC e pela PM, que os questionaram sobre todo o processo. Finalizado esse momento, as professoras solicitaram os registros individuais sobre a atividade, utilizando escrita e/ou desenhos.

\section{Aula 4: a pressão da água}

No início da aula, a PC entregou e discutiu com os alunos o texto "A pressão da água" (CARVALHO, 2016, p. 159), a fim de sistematizar o conhecimento abordado nas aulas anteriores, instigando-os a estabelecer relações entre o texto e o experimento "Molhando as plantinhas". O momento da leitura tornou-se mais uma oportunidade para os alunos discutirem entre si e com a professora os conceitos abordados no problema, pois, durante a sistematização coletiva, fizeram a relação do experimento estudado com situações do dia a dia e foram questionados sobre a possível relação com a horta escolar, no intuito de relacioná-lo com os sistemas de irrigação, conteúdo da aula seguinte. No final da aula, a PC e a PM fizeram um levantamento, junto com os alunos, sobre os elementos que, além do sistema de irrigação, influenciam a produção de alimentos da horta.

\section{Aulas 5, 6 e 7: sistema de irrigação da horta escolar}

Os alunos receberam o texto "Alguns sistemas de irrigação" (CARVALHO, 2016, p. 160-163), contendo características e imagens de vários sistemas de irrigação. A seguir, a PC dividiu a sala em grupos e iniciou a aula com as seguintes questões: "Qual é o tipo de sistema de irrigação utilizado na horta escolar?"; “Quais os materiais utilizados para sua construção?”; "Este sistema promove a economia de água?”.

Os grupos foram até a horta escolar, observaram, fizeram anotações e comentaram que houve mudança no sistema de irrigação da horta, devido a problemas no seu funcionamento. Com base no texto, fizeram a análise de ambos: o sistema de irrigação fixo (com a utilização de mangueiras perfuradas) e o sistema de irrigação 
móvel, por aspersão. De volta à sala de aula, com os alunos sentados em círculo, foi feita a discussão sobre as respostas de cada grupo para as questões apresentadas e a relação dos diferentes sistemas de irrigação com a pressão necessária para seu funcionamento. A PC usou um projetor multimídia para mostrar imagens de diversos sistemas de irrigação, o que contribuiu para que os alunos também fizessem observações em relação aos pontos positivos e negativos de cada sistema observado na horta escolar, bem como de outros sistemas observados no texto, nas imagens e no seu dia a dia. Na sequência, fizeram registro escrito e desenhos sobre a atividade e as conclusões obtidas.

\section{Aula 8: observando a pressão em situações reais}

Inicialmente, a PC propôs quatro exercícios envolvendo a relação entre a variação da pressão hidrostática e a altura de uma coluna d'água (CARVALHO, 2016, p. 147-148). O primeiro mostrava uma casa de dois andares e seu sistema hidráulico, pedindo que os alunos identificassem em que pontos da casa a pressão da água das torneiras seria maior. Nos exercícios 2 e 3, a mesma ideia foi explorada, mas envolvendo um grupo de mergulho e as estruturas utilizadas nas construções de barragens, respectivamente. No último exercício, os alunos deveriam analisar os sistemas de irrigação da horta escolar e argumentar sobre a relação deles com a pressão.

\section{Aula 9: qual a importância da análise do solo e como realizá-la?}

$\mathrm{Na}$ aula, um elemento citado pelos alunos como sendo importante para a produção da horta escolar foi introduzido: o estudo dos tipos de solo. Um agrônomo da região foi até a sala de aula e explicou à turma a importância do estudo do solo para que o plantio seja potencializado, a forma correta de coletar amostras de solos para análises químicas, além de técnicas específicas para a realização de uma análise física básica de solos.

Os alunos fizeram perguntas e o agrônomo fez a coleta de uma amostra do solo da horta para verificar, por meio de análise laboratorial, a necessidade de correção do solo.

\section{Aulas 10, 11 e 12: qual o tipo de solo existente na horta escolar?}

Para atividade seguinte, foram utilizadas três aulas consecutivas. A PG, após dividir a sala em grupos, propôs a questão: "Qual o tipo de solo existente na horta escolar?" e distribuiu o material necessário para a coleta e a análise física de 
amostras de solo: saquinhos plásticos; folhas de papel; copos descartáveis; colheres; água; tabela para anotação dos dados da análise; e livro didático de Geografia.

Cada grupo recolheu até três amostras do solo da horta, mas nem todos seguiram as orientações dadas pelo agrônomo na aula anterior. Na sequência, discutiram entre si as características físicas das amostras bem como a forma como a coleta foi realizada e sua interferência nos resultados da análise. Os alunos utilizaram o livro didático para tentar classificar as amostras de solo de acordo com as características levantadas e preencher a tabela com dados sobre textura, consistência, permeabilidade e cor.

Após essa etapa, os alunos sentaram em círculo e cada grupo apresentou seus resultados e seu método de coleta e análise do solo, explicando o porquê de cada procedimento adotado. A PG e a PM mediaram a discussão, destacando os pontos positivos e negativos que cada grupo adotou, questionando os alunos sobre os fatores que influenciaram os diferentes resultados obtidos pelos grupos. Os alunos também comentaram sobre os procedimentos adotados para as plantações de hortaliças, soja e cana-de-açúcar nas fazendas em que moram, desde a escolha do terreno para a plantação até o manejo utilizado para analisar e corrigir o solo. Depois, fizeram registros individuais da resolução do problema utilizando escrita e/ou desenhos.

\section{Aula 13: estudando sobre diferentes tipos de solos}

Para contextualizar e aprofundar o conteúdo abordado na atividade anterior, a PG usou um projetor multimídia para apresentar imagens de diferentes tipos de solo e explicar sobre o seu processo de formação e as suas principais características, resgatando aquelas observadas na análise feita pelos alunos.

\section{Aula 14: comparação de análises do solo}

O agrônomo voltou à sala de aula para apresentar os resultados da análise de solo, feita no laboratório, e compará-los com os obtidos pelos alunos. Em seguida, a PG propôs a questão: "Diante da análise de solo apresentada, quais os procedimentos necessários para melhorar a capacidade produtiva da horta escolar?". Os alunos, divididos em grupos, iniciaram o debate sobre procedimentos para melhorar a qualidade do solo e, consequentemente, a produção de hortaliças, mas não conseguiram chegar a uma conclusão sobre métodos eficazes. A PG pediu que os estudantes verificassem com seus familiares quais as técnicas utilizadas para melhorar o solo e as apresentassem na aula seguinte, o que trouxe à tona 
questões sobre uso de fertilizantes, métodos caseiros para melhorar o solo, uso excessivo de fertilizantes e pesticidas e produção de produtos orgânicos.

\section{Aula 15: estudando sobre a área dos canteiros}

Na sequência, foi introduzido outro elemento importante para a produção de hortaliças na escola, a área da horta, que é subdivida em canteiros visualmente retangulares. A PM iniciou a aula apresentando o seguinte problema: "Podemos aumentar a produção de alimentos da horta escolar pelo aumento da área plantada. Observando a área ocupada pela horta escolar e pelos canteiros já existentes, seria possível aumentar essa quantidade? Se verificar essa possibilidade, em quantos metros quadrados a área plantada poderia ser aumentada?".

A PM encaminhou os alunos até a horta e entregou réguas e trenas aos grupos, que discutiram entre si as ações necessárias para a resolução do problema. Os grupos identificaram os canteiros existentes como sendo retângulos e mediram suas dimensões, fazendo aproximações decimais. Perceberam, então, que deveriam calcular a área total ocupada pelos canteiros e a área total ocupada pela horta escolar. Assim, decidiram dividir a horta em partes, para que os grupos realizassem as medições em cada uma e, posteriormente, tivessem todos os dados necessários para a resolução do problema.

Durante a sistematização coletiva, a PM questionou sobre as características necessárias para que um quadrilátero seja considerado como retângulo, os alunos argumentaram sobre a resolução do problema e, em seguida, fizeram o registro individual referente ao problema de matemática.

\section{Considerações sobre a SD}

Devido à proximidade das férias e a entrega dos resultados finais, apenas três alunos da turma continuaram a frequentar as aulas após a aula 15, de forma que a aplicação da SD não pôde ser concluída. Sendo assim, serão descritos os objetivos das três aulas restantes bem como os problemas que seriam apresentados aos alunos.

Na aula 16, os alunos deveriam realizar o cálculo das áreas dos canteiros utilizando malhas quadriculadas. Na aula 17, deveriam responder os problemas: "Respeitando as distâncias necessárias entre os canteiros, quantos canteiros retangulares ainda poderão ser construídos na horta escolar?"; "Considerando que a horta tenha apenas canteiros retangulares, podemos construir 
um canteiro que possua todos os seus lados com a mesma medida?"; "Indique possíveis medidas para os lados dos canteiros". Os alunos deveriam investigar quais as distâncias necessárias entre os canteiros e fazer estimativas de valores para as dimensões dos canteiros. Finalmente, na aula 18, os grupos deveriam delimitar os novos canteiros na horta escolar, utilizando as medidas estimadas na aula 17, argumentando sobre os motivos para a escolha da localização de cada canteiro.

\section{Relações interdisciplinares: as aproximações, os distanciamentos e as contribuições para o processo de ensino e aprendizagem}

A ideia de elaborar uma proposta interdisciplinar partiu da PM, que, após uma conversa com a PC e a PG, verificou que as três tinham um mesmo desejo: alterar sua prática docente a fim de resolver os problemas detectados na turma de $6^{\circ}$ ano. A PM, que é uma das autoras deste trabalho, é licenciada em Matemática, atuava na escola há um ano e meio, sendo essa sua primeira experiência profissional, e era aluna de um curso de mestrado profissional em Educação para Ciências e Matemática.

Sabe-se que a implementação de qualquer trabalho interdisciplinar nas escolas depende dos professores. Sendo assim, esta pesquisa visa apresentar as percepções das professoras (PC e PG) em relação ao trabalho desenvolvido, buscando detectar as dificuldades encontradas, as contribuições e as limitações da SD para o processo de ensino e aprendizagem dos alunos.

A coleta de dados foi realizada por meio de entrevistas semiestruturadas e observações assistemáticas, como proposto por Appolinário (2011), o que apresenta a necessidade de uma análise qualitativa, de acordo com Ludke e André (2012).

As questões da entrevista tiveram como objetivo conhecer o perfil das professoras e sua percepção quanto à proposta interdisciplinar, à turma, às metodologias utilizadas, às possíveis mudanças detectadas no comportamento dos alunos e às dificuldades encontradas. É importante ressaltar que o objetivo não era avaliar as professoras envolvidas, mas verificar seu posicionamento em relação ao trabalho desenvolvido.

De acordo com as entrevistas, sabe-se que as professoras são jovens (têm menos de 30 anos de idade) e possuem pouca experiência docente. A PG é moradora da zona rural e começou sua vida estudantil nessa mesma escola. Após concluir o curso de licenciatura em Geografia, retornou à escola como professora de Geografia e História, em 2013, e era a responsável pelo plantio na horta escolar. A PC não é formada na área, cursou licenciatura em Educação Física e trabalhou em projetos 
sociais ligados à sua área de formação, vindo a ter sua primeira experiência docente no ano do desenvolvimento deste trabalho.

O descontentamento das professoras quanto aos resultados do seu trabalho motivou-as a repensar suas aulas, que eram expositivas e baseadas no livro didático. A PC justifica que era "presa ao livro" por ser sua primeira experiência docente e, como não é formada na área, não sabia agir de outra forma. A PG conta que também tentava utilizar vídeos, imagens e textos, mas que não obtinha sucesso:

Depois de expor imagens e explicar tudinho para os meninos, depois eu pedia um texto sobre o que eles entenderam, parecia que eu não tinha falado nada, não tinha explicado nada. Aí, tentava um vídeo, e depois pedia um texto do que entenderam, e ficavam assim, parecendo que não entenderam nada. Tudo que pensava, parece que não resolvia. Ficava me sentindo a pior professora do mundo (PG).

Após optarem por desenvolver um trabalho em conjunto, as três professoras discutiram sobre propostas metodológicas para as aulas, e a PM sugeriu que utilizassem atividades investigativas, objeto de estudo do seu trabalho de mestrado, o que foi prontamente aceito pelas colegas. Neste momento, observa-se mais um elemento fundamental para o desenvolvimento de um trabalho interdisciplinar, a disposição das professoras em trabalhar com uma metodologia que até então não conheciam, pois, conforme Pombo:

Só há interdisciplinaridade se somos capazes de partilhar o nosso pequeno domínio do saber, se temos a coragem necessária para abandonar o conforto da nossa linguagem técnica e para nos aventurarmos num domínio que é de todos e de que ninguém é proprietário exclusivo (POMBO, 2005, p. 13).

Durante a elaboração da SD, houve um distanciamento entre as propostas elaboradas pelas professoras envolvidas no que se refere às atividades investigativas, o que exigiu interferência da PM na elaboração e/ou adaptação de algumas atividades. Acredita-se que isso ocorreu não somente pelo pouco conhecimento e tempo de estudo da PC e da PG, mas também pela complexidade que envolve a etapa de elaboração dos problemas que norteiam cada atividade. Porém, no desenvolvimento da SD, houve um diálogo constante entre as professoras, que debateram sobre suas expectativas, o desenvolvimento e os resultados observados em cada uma das aulas.

A construção das etapas da SD e os assuntos abordados mostram a compreensão das professoras sobre como deve ser uma proposta interdisciplinar, o que pode ser verificado na justificativa da PC: 
Ele não tem separado que a horta é só pressão e depois só o adubo no chão, não tem isso separado. [...] O aluno não traz essas informações separadas, então tem que ter um gancho de uma com a outra mesmo, é onde a interdisciplinaridade encaixa perfeitamente. [...] O professor tem essa mania de achar que o aluno separa as coisas pra ir pra aula. Pra aula de ciências, por exemplo, ele fecha a gavetinha da matemática e é só ciências e não tem como fazer isso (PC).

E também na afirmação da PG, ao mostrar a relação entre os conteúdos abordados na SD:

Eles precisavam saber como era a água, como fazer pra ela chegar ali, como era o solo, como distribuir a água. A parte da matemática, de medir as alturas, se ficar baixo o que ia acontecer. Querendo ou não, temos essa relação no dia a dia e a gente não percebe. Só do fato de aqui, eu pegar a água lá do poço e fazer ter queda aqui, eu usei matemática (PG).

Em relação ao comportamento dos alunos durante o desenvolvimento da SD, a PC e a PG disseram que os alunos do $6^{\circ}$ ano tinham muita dificuldade com a escrita e afirmaram que, ao analisar as sistematizações individuais, perceberam uma melhora na argumentação, pois eles apresentaram respostas mais longas e coerentes. A PC declarou ter ficado surpreendida ao observar o desempenho e a participação dos alunos, pois a turma era considerada a mais difícil da escola. A PG também salientou o envolvimento da turma, dizendo que alguns dos alunos que, antes, não faziam nada durante as aulas participaram ativamente das atividades da SD.

Sobre o uso de atividades investigativas nas aulas, as professoras afirmaram ter gostado muito dessa abordagem, conforme se pode notar na fala da PC: "Vê os meninos falarem, e vê que foi você que provocou aquilo no menino, isso te desperta como profissional". As professoras chamaram a atenção para a participação ativa do aluno no seu processo de aprendizagem: "Nas atividades investigativas, o fato de você instigar o aluno a se fazer presente dentro da sala de aula, de corpo, alma e espírito, não só de corpo presente, ele passa a estar ali inteiro naquela aula" (PC). A PG, ao comparar suas aulas anteriores com as investigativas, constata:

Parece que abre um horizonte, uma possibilidade. Bom ver que a gente tem que adequar a metodologia à turma, porque, por mais que eu tentasse um monte de coisas, praticamente dar a resposta para os alunos, não adiantava. Aí, você descobre que não é dar a resposta, é fazer ele buscar, investigar e ir atrás da resposta (PG).

As professoras, ao discutirem os resultados apresentados pelos alunos ao final do desenvolvimento da SD, confirmaram o que disseram nas entrevistas, pois consideraram que a metodologia utilizada contribuiu para a aprendizagem dos alunos e também para a sua formação profissional, por possibilitar conhecer e utilizar uma metodologia que atendeu às suas expectativas docentes. 
Em relação ao papel de mediador que o professor deve assumir no desenvolvimento das atividades investigativas, a PC afirmou não ter tido dificuldades, pois está acostumada a ouvir os alunos: "Eu sou aberta a ouvir o que o aluno tem, porque eles trazem muita informação pra gente. É interessante ver que, quando a gente fecha a boca um pouco e deixa eles falarem, eles tem muita coisa proveitosa pra falarem" (PC). Já a PG disse que ficava ansiosa para dar as respostas para os alunos, pois está acostumada a falar muito durante as aulas, apesar de compreender a necessidade de ouvir o que eles têm a dizer:

[...] sou muito automática dentro da sala de aula, falo muito, vou falando, falando e falando. Então, quando os meninos ficavam tentando pensar no que ia dizer, eu já estava querendo dar a resposta pra eles, porque pra eles foi bom, mas, pra mim, também eu achei uma experiência muito boa, porque quando você vai discutir uma coisa com um aluno, que você vê que ele entende, que ele quer argumentar, o seu sentimento é outro né (PG).

Um ponto positivo bastante destacado pelas professoras para o êxito da proposta foi a relação do tema abordado na SD com a realidade dos alunos. A PC, dentre outros exemplos, cita um momento de sistematização coletiva em que os alunos associaram o experimento "Molhando as plantinhas" a uma situação vivida no assentamento onde moram. Lá, havia duas caixas d'água, e, nas casas localizadas em terrenos mais baixos, a pressão da água nas torneiras é maior, enquanto nas casas que estão em lugares mais altos, a pressão é menor:

Eram muito atentos a tudo, porque é coisa que está lá no dia a dia deles, ou o pai faz ou eles veem, cresceram com aquilo ali. A questão da caixa d'água mesmo, eu achei tão engraçado eles relacionarem, falando que na vila tinha duas caixa d'água, relacionando com o que estava estudando [...]. No meu ponto de vista, eu não imaginava que eles iam conseguir fazer aquelas relações (PC).

A PG afirma que sempre foi uma vontade sua desenvolver um trabalho desse tipo e aponta sua relevância:

O que sempre foi meu sonho era a escola rural ser voltada para o conhecimento rural, a vivência deles [...]. Eles sonham com o dia que vão terminar o nono ano pra poder ir pra cidade, porque acham que só lá existe possibilidades. Não veem a possibilidade de trabalhar e ganhar dinheiro, seu meio de vida, continuando na fazenda. E não veem essa possiblidade porque a gente só ensina, só mostra o que a cidade faz, mas ninguém nunca mostrou para o aluno que a cidade só sobrevive porque existe o campo. Então, eu tinha muita vontade de colocar isso na prática $(\mathrm{PG})$.

Em relação à aprendizagem de conteúdos, a PG destacou que a interdisciplinaridade possibilitou aos alunos uma compreensão mais ampla sobre os assuntos estudados, pois eles perceberam que, para a compreensão da produção da horta escolar, necessitam de conceitos de diversas disciplinas. 
Pode-se notar, em todos os momentos destacados, que as professoras estabeleceram uma postura de parceria, proporcionando o diálogo, a cooperação e a aprendizagem durante o desenvolvimento da SD. Essa postura de parceria e cooperação pode ser detectada também em diversas falas da PC e da PG, durante as entrevistas, pois ambas usam sempre a primeira pessoa do plural par se referir às ações desenvolvidas por elas durante as aulas.

Em relação às dificuldades encontradas para realização de uma proposta interdisciplinar, a PG destacou a falta de tempo dos professores para planejarem juntos, enquanto a PC afirmou que o problema maior é a resistência do próprio professor: "A gente como profissional coloca muita dificuldade, porque a gente quer ficar naquela área que é confortável pra cada um, não quer aumentar muita coisa no serviço da gente" (PC).

Apesar das dificuldades apontadas, a PC e a PG demonstraram o interesse em continuar a desenvolver propostas interdisciplinares. A PG afirmou estar pronta para outros trabalhos, mas deixou claro que isso só é possível se houver um grupo interessado, pois não se consegue desenvolver uma proposta interdisciplinar sozinha. Para a PC, o trabalho parece ter sido bastante positivo, pois disse que foi uma fonte de inspiração pra outras aulas e outros conteúdos, e complementa:

[...] eu quero ter outras oportunidades de trabalhar de forma interdisciplinar, porque eu gostei muito, particularmente achei muito interessante. Já tinha lido sobre o assunto, mas, na escola, como foi trabalhado, eu não tinha feito ainda, então foi muito proveitoso pra mim. Foi uma experiência que todo professor deveria passar. [...] Fomos exemplos vivos disso, que dá certo, que os alunos gostam, participam e contribuem. Muda a dinâmica da aula, instigou até as outras turmas, porque viam os meninos indo pra horta, fazendo os experimentos e indo pro laboratório, como eles diziam. As disciplinas têm que conversar $\operatorname{sim}(\mathrm{PC})$.

\section{Considerações finais}

Este trabalho descreveu uma SD interdisciplinar utilizando atividades investigativas, aplicada em uma turma de $6^{\circ}$ ano do ensino fundamental com dificuldades de aprendizagem, que era apática e desmotivada, em uma escola rural do interior do estado de Goiás. A SD foi desenvolvida pelas professoras de Ciências, Geografia e Matemática da referida turma, que trabalharam em parceria durante todo o processo. Foram analisadas as percepções das professoras quanto às dificuldades encontradas, às contribuições e limitações da SD para os alunos e ao trabalho interdisciplinar desenvolvido.

De acordo com os resultados obtidos, pode-se concluir que a SD proporcionou mudanças significativas na participação e na aprendizagem dos alunos. O fato de a 
SD partir de assuntos do seu cotidiano contribuiu para que os alunos compreendessem situações do seu dia a dia e percebessem a necessidade de estudar diferentes conteúdos para responder a questão proposta: "Como aumentar a produtividade da horta escolar?". Outro aspecto verificado pelas professoras é que a SD motivou os alunos na busca por suas próprias respostas e os aproximou das ciências, por intermédio do relacionamento entre a ciência escolar e a realidade.

Abordar sequências didáticas interdisciplinares por meio de atividades investigativas não é fácil, pois requer, dos professores, muito mais do que leituras sobre os pressupostos teóricos envolvidos e exige um entendimento de que o processo de ensino se dá na relação entre teoria e prática, pois é nesses momentos que se pode observar a dinâmica do ensino investigativo. O professor necessita assumir uma postura de mediador e saber elaborar perguntas capazes de levar os alunos a refletir sobre o conteúdo abordado e argumentar sobre tal, o que pode ser um problema para alguns, como aconteceu com a professora de Geografia.

É importante ressaltar que o desenvolvimento deste trabalho propiciou às professoras realizar uma reflexão quanto a suas práticas pedagógicas, já que puderam observar as mudanças na participação dos alunos e na dinâmica de sala de aula, bem como os reflexos na aprendizagem dos conteúdos abordados.

Este trabalho não tem a pretensão de solucionar o problema educacional do país, mas, apontar um caminho, dentre outros, que pode ser utilizado com o intuito de auxiliar os alunos a buscarem suas próprias respostas para questões que lhes são postas, podendo contribuir, assim, para uma educação efetiva. Diante disso, espera-se que a SD apresentada possa contribuir com outros professores e motivar outras pesquisas sobre o assunto.

\section{Nota}

1 Disponível em: <http://paje.fe.usp.br/estrutura/midiavirtual.html>. Acesso em: 15 out. 2016.

\section{Referências}

APPOLINÁRIO, Fábio. Metodologia da ciência: filosofia e prática da pesquisa. São Paulo: Cengage Learning, 2011.

AUGUSTO, Thaís G. S. et al. Interdisciplinaridade: concepções de professores da área de Ciências da Natureza em formação em serviço. Ciência \& Educação, São Paulo, v. 10, n. 2, p. 277-289, 2004.

CARVALHO, Anna Maria Pessoa. Ensino de Física. São Paulo: Cengage Learning, 2010. 
. O ensino de Ciências e a proposição de sequência de ensino investigativas. In:

(Org.). Ensino de Ciências por investigação: condições para implementação em sala de aula. São Paulo: Cengage Learning, 2013. p. 1-20.

CARVALHO, Núbia Patielle Assis. Horta escolar: contribuições da interdisciplinaridade e de atividades investigativas para a alfabetização científica. 2016. Dissertação (Mestrado em Ensino de Ciências e Matemática) - Instituto Federal de Goiás, Jataí, GO, 2016. Disponível em: <http:// www.ifg.edu.br/attachments/article/1279/Disserta\%C3\%A7\%C3\%A3o-N\%C3\%BAbia\%20Patielle\%20Assis\%20Carvalho-2016\%20(.pdf\%205.275\%20kb).pdf>. Acesso em: 20 jan. 2018.

CARVALHO, Núbia Patielle Assis; SOUZA, Paulo Henrique de. Molhando as plantinhas: contribuições de atividades investigativas para a alfabetização científica. In: SIMPÓSIO NACIONAL DE ENSINO DE FÍSICA, 22, 2017, São Carlos, SP. Programa. Disponível em: <http://www1. sbfisica.org.br/eventos/snef/xxii/sys/resumos/T1241-1.pdf>. Acesso em: 20 jan. 2018.

LUDKE, Menga; ANDRÉ, Marli Elisa Dalmazo. Abordagens qualitativas. São Paulo: EPU, 2012.

POMBO, Olga. Interdisciplinaridade e integração dos saberes. Liinc em Revista, Rio de Janeiro, v. 1, n. 1, p. 3-15, mar. 2005.

Epistemologia da interdisciplinaridade. Revista do Centro de Educação e Letras, Foz do Iguaçu, v. 10, n. 1, p. 9-40, 2008.

POZO, Juan Ignácio; CRESPO, Miguel Ángel Gomez. A aprendizagem e o ensino de ciências: do conhecimento cotidiano ao conhecimento cientifico. Tradução de Naila Freitas. 5. ed. Porto Alegre: Artmed, 2009.

ROSA, Cleci Teresinha Werner da; ROSA, Álvaro Becker da; GIACOMELLI, Alisson Cristian. Interdisciplinaridade e o contexto escolar: investigações a partir de uma atividade lúdica de interesse dos estudantes. Ciência e Natura, Santa Maria, v. 38, n. 1, p. 535-543, 2016. Disponível em: <http://www.redalyc.org/articulo.oa?id=467546196049>. Acesso em: 28 jan. 2018.

SASSERON, Lúcia Helena. Alfabetização científica no ensino fundamental: estrutura e indicadores deste processo em sala de aula. 2008. Tese (Doutorado em Educação) - Faculdade de Educação, Universidade de São Paulo, São Paulo, 2008.

. Interações discursivas e investigação em sala de aula: o papel do professor. In: CARVALHO, Anna Maria Pessoa de (Org.). Ensino de Ciências por investigação: condições para implementação em sala de aula. São Paulo: Cengage Learning, 2013. v. 1. p. 41-62.

SASSERON, Lúcia Helena; CARVALHO, Anna Maria de Pessoa. Alfabetização científica: uma revisão bibliográfica. Investigações em Ensino de Ciências, Porto Alegre, v. 16, n. 1, p. 59-77, 2011.

TRINDADE, Diamantino Fernandes. Interdisciplinaridade: um novo olhar sobre as Ciências. In: FAZENDA, Ivani (Org.). O que é interdisciplinaridade. São Paulo: Cortez, 2008. p. 65-83.

ZABALA, Antoni. A prática educativa: como ensinar. Porto Alegre: Artmed, 1998. 